\title{
CHEMICAL AND CHEMOTACTIC STIMULATION OF FEEDING BEHAVIOR IN THE HERMIT CRAB PETROCHIRUS DIOGENES*
}

\author{
BRIAN A. HAZLETT \\ Department of Zoology, University of Michigan, Ann Arbor, Michigan 48104
}

(Received 24 October 1970)

\begin{abstract}
Various concentrations of fish juice were introduced to appendages of freely moving specimens of Petrochirus diogenes.

1. The threshold concentration for chemical elicitation of feeding behavior was over ten times as high for the ambulatory dactyls as for the antennules.

2. Combining tactile input with chemical input decreased the behavioral threshold of the dactyl receptors ten-fold.

3. Ablation of the antennules was followed, over a two-week period, by a 100-fold increase in behavioral sensitivity to dactyl stimulation.
\end{abstract}

\section{INTRODUCTION}

THE USE of the antennules as distance chemoreceptors is well known in decapod crustacea (Bullock \& Horridge, 1965; Hazlett, 1968; Laverack, 1968; Ache \& Case, 1969), as is the presence of chemoreceptive units on the walking legs of many decapods (Case \& Gwilliam, 1961 ; Hodgson, 1958). However, there have been few studies measuring the relative thesholds of the two sets of receptors in the same species. This information is necessary for an analysis of normal feeding behaviour.

The present behavioral study was undertaken to determine something about the nature of the receptors on the antennules and ambulatory leg dactyls in one species of anomuran crab and to look for interaction in the input from these two areas.

\section{MATERIALS AND METHODS}

The specimens of Petrochirus diogenes used were flown from Big Pine Key, Florida, to Ann Arbor, Michigan, and maintained in aquaria filled with sea water made with Instant Ocean brand salts. The water temperature was approximately $23^{\circ} \mathrm{C}$ but was not controlled. Specimens were fed every 3-4 days (except where noted) and were held in individual containers to facilitate treatment and identification and to prevent cannibalism. All were adult animals between 4 and $8 \mathrm{~cm}$ in cephalothorax length. Animals were induced to come out of their gastropod shells, in order to ablate antennules, by tapping on the shells with a light hammer, thus simulating the shell fighting behavior of an attacking crab (Hazlett, 1966).

Three types of chemical input were used, all based upon pieces of fish (frozen cod). (1) In some tests, pieces of fish were touched to appendages. (2) In most of the tests, a $2 \cdot 5 \mathrm{-g}$ piece of fish was thoroughly macerated in $100 \mathrm{ml}$ of sea water and the resulting solution filtered through medium-grade filter paper. This is referred to as "filtered fish juice". Various dilutions $(1: 10-1: 10,000)$ of full strength filtered fish juice were made to

* Supported by Grant MH-02487 from the National Institutes of Mental Health. 
test behavioral thresholds. A small quantity of fuorescein was added to all solutions as a visual marker, to make it possible to see when a solution reached an appendage. (3) A solid chemical stimulus (of varying fish juice concentration was made with pellets of polyacrylamide gel (Davis, 1964), using various dilutions of filtered fish-juice as the water component of the gel.

A clean glass rod was used to apply a pure tactile stimulus.

All solutions (test and controls of sea water + fuorescein) were introduced to the area just around the appendage being tested via a hypodermic syringe attached to a polyethylene tube which had an internal bore of $1 \mathrm{~mm}$. Pieces of fish or polyacrylamide gel were held with metal forceps as physical contact with an appendage was made.

Feeding elicitation thresholds for the antennules and dactyl receptors were determined for an animal by introducing small amounts of solution $\left(0.5 \mathrm{~cm} .^{3}\right)$ just around one dactyl or just around the antennular flagellae. An animal was always fed $48 \mathrm{hr}$ prior to testing and never fed during that $48 \mathrm{hr}$ period. A control solution of fluorescein in sea water was introduced first, reactions noted, and followed in $5 \mathrm{~min}$ by a dilution of filtered fish juice; occurrence and duration of feeding activity was recorded. If no feeding activities were shown, the animal was placed in a clean container of sea water, left for 15 min and tested with the next stronger solution (e.g. if the animal failed to show a reaction to the $1: 1000$ solution, it was tested with the $1: 100$ dilution). If the animal did show a reaction to the first test solution, it was placed in a clean container, left $15 \mathrm{~min}$, and tested with the next weaker solution (e.g. $1: 10,000$ ).

Chemotactic input to the antennules was tested by lightly touching pieces of polyacrylamide gel to an antennule flagellum of a crab. Gel was used in the same way in testing the dactyl receptors. In addition, hairs on the distal third of the dorsal surface of the dactyls of the first pair of ambulatory legs were touched with a clean glass rod (1) before chemical stimulation of the antennules and (2) just after such stimulation (before any odor had reached the ambulatory legs). Pieces of fish were also touched lightly to the dactyl hairs. The interaction of chemical and tactile input to the ambulatory dactyls was also tested (1) by the application of touch of a glass rod to the dactyl hairs followed by the introduction of filtered fish juice and (2) by the introduction of filtered fish juice followed (within 1 sec) by touch with a clean glass rod.

The behavioral threshold of the dactyl receptors was tested in a number of intact crabs and then both antennules ablated. The thresholds were determined for these animals every $4-5$ days for about $2 \frac{1}{2}$ weeks following the ablation. In a few animals, the antennules were not ablated, but were patted dry and coated with Eastman 910 contact adhesive. In the case of two of these antennule-coated animals, after the dactyl threshold determinations, an attempt was made to scrape the contact cement off, and final tests were run.

\section{RESULTS}

\section{Normal animals}

When a small quantity of filtered fish juice reached the antennular flagellae, an individual of $P$. diogenes would show a 1-3-min burst of behaviour patterns characteristic of feeding (Hazlett, 1968). These patterns included increased locomotion, cheliped waving, ambulatory leg waving and digging novenuents, and increased rate of maxilliped beating. These behaviour patterns were shown not only to full-strength filtered fish-juice but to dilutions as low as $1: 10,000$ (the lowest used), but not to control solutions of fluorescein + sea water. Of the fifteen intact crabs tested, seven reacted to $1: 1000$ but not to $1: 10,000$; the other eight reacted to all test solutions. When pieces of polyacrylamide gel made with filtered fish juice were 
touched to the antennule flagellae, the antennules were often rapidly pulled back and in some cases, the crab pulled back into its shell. Feeding patterns were elicited by this chemotactic input in four of six crabs by gel containing $12.5 \%$ filtered fish juice. Two showed feeding when touched with $1.2 \%$ fish-juice gel, one to $0.1 \%$ fish-juice gel and none to $0.01 \%$ fish-juice gel. Thus, the antennules are more effectively stimulated when touch is not applied.

Tactile stimulation of the ambulatory dactyls with a clean glass rod did not elicit any feeding patterns in the ten animals tested. However, if the antennules were first stimulated by a supra-threshold concentration of fish juice and tactile contact of the dactyl hairs made within one second after antennal stimulation, all five crabs tested lunged at the glass rod. Tactile input may guide the execution of feeding behaviours, although not necessary for initially eliciting them. A similar co-ordinated lunge was elicited in all animals tested by touching the dactyl hairs with a piece of fish. However, a piece of fish, held $5 \mathrm{~mm}$ from the dactyl hairs for 1 min (five intact crabs tested) did not elicit feeding.

Application of full strength fish juice or $10 \%$ fish juice just around one ambulatory dactyl elicited short bursts (less than $30 \mathrm{sec}$ long) of feeding activities in all ten crabs tested, while $1 \%$ fish juice elicited feeding in four, 0.1 per cent in two and $0.01 \%$ fish juice did not elicit feeding in any of the ten crabs tested. These results are summarized in Fig. 1.

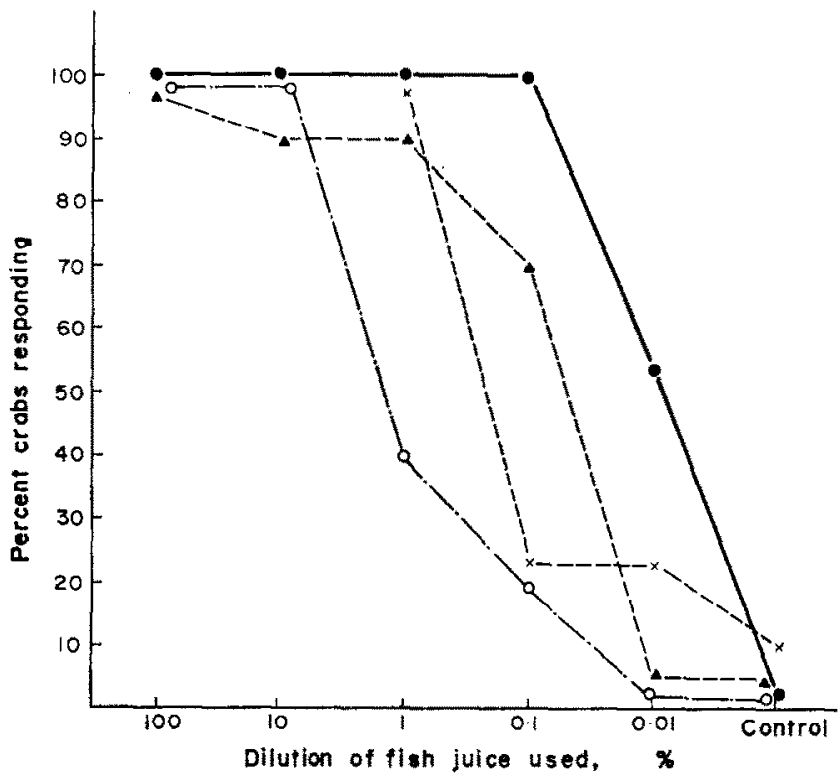

Fic. 1. Relationship between concentration of fish juice and percent of crabs showing feeding behaviors when that concentration is introduced just around the antennules (-), just around an ambulatory dactyl $(0-0)$, just around a dactyl and the dactyl touched with a glass rod $(\boldsymbol{\Delta}-\boldsymbol{\Lambda})$, or the dactyl touched with gel containing fish juice $(x-x)$. 
When dactyl hairs were touched with a clean glass rod $1 \mathrm{sec}$ after introduction of a test solution around that dactyl, none of the crabs showed any response to the sea water + fluorescein control, nine of ten to $10 \%$ fish juice and $1 \%$ fish juice, seven to $0.1 \%$ fish juice, and none to $0.01 \%$ fish juice. Using pieces of polyacrylamide gel, all 5 crabs tested responded to $1 \cdot 25 \%$ fish juice, but just two responded to 0.12 per cent and 0.01 per cent and one of these two crabs also responded to plain gel (and was thus discounted in calculating thresholds). These results are also summarized in Fig. 1. Combining tactile input with chemical input decreased the dactyl behavioural threshold by about two orders of magnitude.

\section{Ablation experiments}

Threshold levels for the dactyl receptors decreased following antennule ablation as shown in Fig. 2. After about two weeks, the threshold level of the dactyl receptors was about the same as that of the antennules of intact crabs. This experiment was carried out for $15 \mathrm{crabs}$, divided among three separate replications.

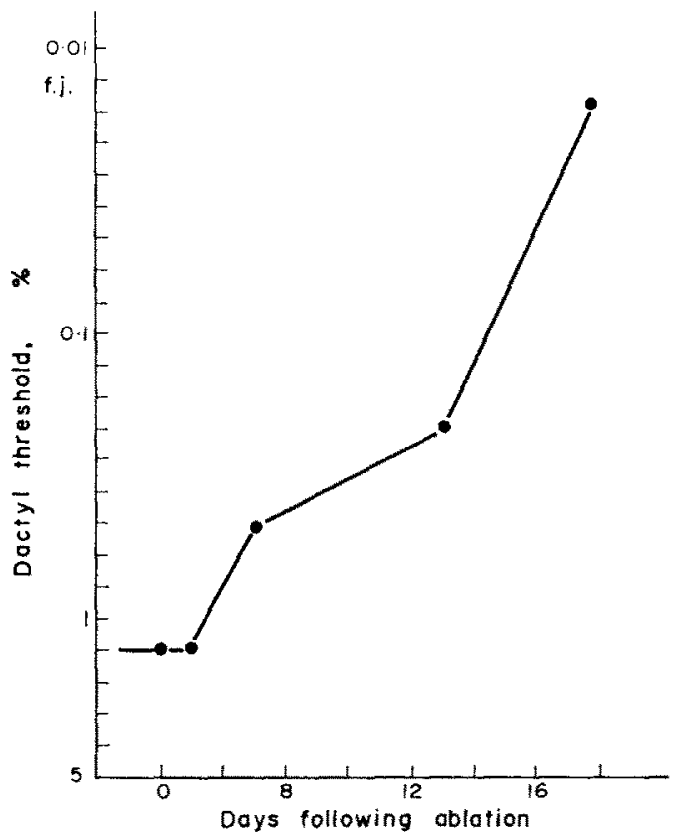

FIG. 2. Change in average behavioral threshold for dactyl stimulation following antennule ablation.

The antennules of four crabs were coated with contact adhesive. When tested 14 days later, two of these showed feeding responses when test solution was placed just around the antennules. Their dactyl receptor threshold was unchanged from the pre-treatment level. For the two that showed no response to antennule stimulation, the threshold of the dactyl receptors had decreased from a mean of 0.5 per 
cent (two intact tests for each animal) to $0.05 \%$ fish juice. Five days after trying to scrape the adhesive off the antennules, one of the crabs showed a reaction to antennule stimulation, i.e. the antennal chemoreceptors were at least partially functional, and the dactyl threshold was $0 \cdot 1 \%$ fish juice (one test).

\section{DISCUSSION}

Under normal circumstances it would appear that in $P$. diogenes, the first site of chemical elicitation of feeding activity is the antennule flagellum. Input from the antennules would result in digging-searching-grabbing movements, by the ambulatory legs as well as other activities. A number of objects might be grasped when tactile contact is made (see also Hazlett, 1968), before a food object is shoved towards the mouth appendages by the ambulatory legs. The latter behaviour would occur primarily when the proper chemo-tactic input from the dactyl receptors was received. The approximately ten-fold difference in sensitivity to water-borne chemicals means the antennules would almost always be stimulated first.

The more than tenfold increase in chemical responsitivity when tactile and chemical input to the dactyl occurs almost simultaneously indicates the dactyl hairs as true chemotactile organs. However, the behavioral techniques used are far from precise enough to say that one hair or even one particular group of hairs on the dactyl were stimulated. An electrophysiological approach will be necessary to determine where the chemical and tactile inputs are added. It is known in some insects (Phormia) that a single hair can respond to both chemical and tactile input (Dethier, 1963).

The increase in behavioral sensitivity to dactyl stimulation following removal of antennular input is quite marked. Clearly a crab, in nature, that had lost antennal function, would be able to compete with intact conspecifics in food detection after a rather short time; large Petrochirus easily survive 3 weeks or longer without any food. The undefined molecular composition of the basic test solution used in these experiments $(2.5 \mathrm{~g}$ of frozen cod in $100 \mathrm{ml}$ sea water) raises questions of the constancy of the chemical stimulus from day to day (new fish juice was made each day of testing). This is at least partially controlled for by the observed result that intact animals, for example, were rather consistent in their reactions to a given concentration. The inter-animal variation on any day was as great as the inter-day variation of any class of receptors. In all cases of testing individuals which had been antennule-less for some days, intact crabs were tested the same day with the same solutions.

It is not possible, from these behavioral observations, to even suggest where the nervous system changes are occurring which result in the changes in behavioral threshold. The possibility of active peripheral inhibition of dactyl input by input from the antennules cannot be ruled out, although more central changes in the analysis of input would seem more likely.

Acknowledgements-Thanks are given to B. Oakley for many discussions of the work and to S. Easter and B. Oakley for their comments on the manuscript. 


\section{REFERENCES}

ACHE B. \& CASE J. (1969) An analysis of antennular chemoreception in two commensal shrimps of the genus Betaeus. Physiol. Zoöl. 42, 361-371.

Bullock T. H. \& Horridge G. A. (1965) Structure and Function in the Nervous System of Invertebrates., Freeman, San Francisco.

CASE J. \& Gwilliam G. F. (1961) Amino acid sensitivity of the dactyl chemoreceptors of Carcinides maenas. Biol. Bull. 121, 449-455.

Davis B. J. (1964) Disc electrophoresis-II. Method and application to human serum proteins. Ann. N.Y. Acad. Sci. 121, 404-427.

Dethier V. G. (1963) The Physiology of Insect Senses. Methuen, London.

Hazlett B. A. (1966) Social behavior of the Paguridae and Diogenidae of Curaçao. Stud. Fauna Curafao, 23, 1-143.

HazLetT B. A. (1968) Stimuli involved in the feeding behavior of the hermit crab Clibanarius vittatus (Decapoda, Paguridea). Crustaceana 15, 305-311.

HoDGSON E. S. (1958) Electrophysiological studies of arthropod chemoreception-III. Chemoreceptors of terrestrial and fresh water arthropods. Biol. Bull. 115, 114-125.

Laverack M. (1968) On the receptors of marine invertebrates. Oceanogr. Mar. Biol. Ann. Rev. 6, 249-324.

Key Word Index-Feeding; chemotaxis; fish juice; hermit crab; receptors to chemicals; Petrochirus diogenes. 